\title{
INSIGHTS INTO THE REACTION MECHANISM BETWEEN AZACYCLOPROPENYLIDENE AND AZACYCLOPROPANE: A THEORETICAL STUDY
}

\author{
XIAOJUN TAN ${ }^{*, a}$, WEIHUA WANG ${ }^{b}$, PING LI*,b \\ $\left({ }^{a}\right.$ College of Biological Science and Technology, University of Jinan, Jinan, Shandong, 250022, People's Republic of China) \\ ('School of Chemistry and Chemical Engineering, Qufu Normal University, Qufu, Shandong, 273165, People's Republic of China)
}

\begin{abstract}
The reaction mechanism between azacyclopropenylidene and azacyclopropane has been systematically investigated employing the second-order MøllerPlesset perturbation theory (MP2) method to better understand the azacyclopropenylidene reactivity with three-membered ring compound azacyclopropane. Geometry optimization, vibrational analysis, and energy property for the involved stationary points on the potential energy surface have been calculated. For the first step of this reaction, azacyclopropenylidene can insert into azacyclopropane at its $\mathrm{C}$-N bond to form a spiro intermediate IM. Through the ring-opened step at $\mathrm{C}-\mathrm{C}$ bond of azacyclopropenylidene fragment, IM can transfer to product P1, which is named as pathway (1). On the other hand, through the $\mathrm{H}$-transferred step and subsequent ring-opened step at C-N bond of azacyclopropenylidene fragment, IM can turn into product P2, which is named as pathway (2). From the thermodynamics viewpoint, the $\mathrm{P} 2$ is the dominating product. From the kinetic viewpoint, the pathway (1) of formation to P1 is primary.
\end{abstract}

Key words: Azacyclopropenylidene, Azacyclopropane, Reaction mechanism, MP2

\section{INTRODUCTION}

Carbon chain molecules containing heteroatoms $\left(\mathrm{N}^{1-8}, \mathrm{O}^{9,10}, \mathrm{~S}^{11-13}, \mathrm{Si}^{14-16}\right)$ have been paid much attention recently due to their astrophysical abundance and interesting spectroscopic properties. Typical example is cyanopolyacetylenes $\mathrm{HC}_{2 \mathrm{n}+1} \mathrm{~N}$, in which $\mathrm{HC}_{11} \mathrm{~N}$ is one of the largest carbon chain molecules observed in interstellar medium ${ }^{17}$. In contrast to cyanopolyacetylenes $\mathrm{HC}_{2 n+1} \mathrm{~N}$, systematic study on the molecules $\mathrm{HC}_{2 \mathrm{n}} \mathrm{N}$ containing even number of carbon atoms was relatively scarce. In spite of this, the $\mathrm{HC}_{2 \mathrm{n}} \mathrm{N}$ molecules and their geometrical isomers are still very important, for they are good candidates for astrophysical observation by microwave and infrared spectroscopy due to the rather large dipole moments of these molecules. What's exciting is that $\mathrm{HC}_{2} \mathrm{~N}$ has been observed in interstellar space ${ }^{18}$. Many experimental and computational methods were carried out for the structures and the relative energies of some isomers of this system. A lot of studies have revealed that there exist many isomers with different kind of geometries (linear, bent or cyclic) or different multiplicity (singlet or triplet) having similar energies for the $\mathrm{HC}_{2} \mathrm{~N}$ molecules ${ }^{19-30}$. Lee et $a l$. have characterized the quasilinear triplet, bent singlet, and cyclic singlet $\mathrm{HC}_{2} \mathrm{~N}$ isomers and determined their molecular properties with a series of highly accurate $a b$ initio level of theory ${ }^{27}$. In addition, the cyclic $\mathrm{HC}_{2} \mathrm{~N}$ isomer was found to be an intermediate between the interconversion of the bent HCCN and the unknown bent $\mathrm{HCNC}$ on the hypersurface of neutral, anionic, and cationic species where the barriers are feasible ${ }^{31}$. The most stable singlet state of $\mathrm{HC}_{2} \mathrm{~N}$ molecule is named as azacyclopropenlydiene, which structure confirmed by spectroscopy and calculation is displayed in scheme 1 .

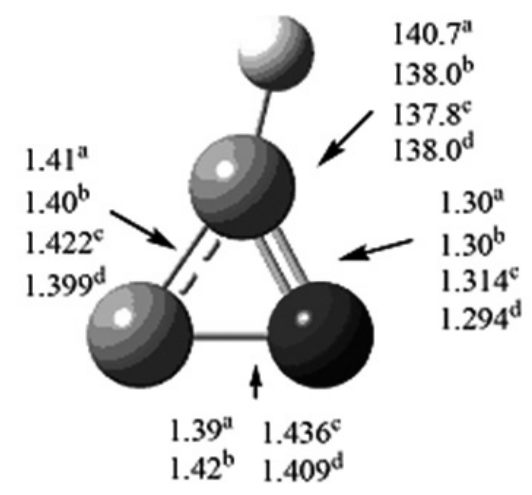

Scheme 1. Geometrical parameters for azacyclopropenylidene calculated at diverse levels, which bond lengths are in $\AA$ and bond angles in degree. (a: B3LYP/6-311++G**28; b: MP2/6-311++G**28; c: QCISD(T)/D95**21; d: $\left.\operatorname{CCSD}(\mathrm{T}) / \mathrm{cc}-\mathrm{pVTZ} \mathrm{Z}^{30}\right)$
In 1998, matrix generations of singlet azacyclopropenylidene and singlet bromocyanocarbene $(\mathrm{BrCCN})$ were researched by Maier and co-workers ${ }^{32}$. Casavecchia et al. reported the dynamics of a reaction of nitrogen atom with an unsaturated hydrocarbon by combining crossed molecular beam experiments and $a b$ initio molecular orbital calculations. They found that azacyclopropenylidene is one of the products of the reaction of nitrogen atom with $\mathrm{C}_{2} \mathrm{H}_{2}$ in the upper atmosphere of Titan ${ }^{33}$. Thus, the azacyclopropenylidene seems to be a good candidate for astrophysical detection, considering these various possible formation pathways and its large dipole moment ${ }^{34}$.

Computation of $\mathrm{HC}_{2} \mathrm{~N}$ molecules will be helpful to elucidate the reactivity and kinetic stability of these molecules, but less attention has been paid to the reactivity of azacyclopropenylidene with the active species containing small ring compounds until now. As a N-heterocyclic compound, the reaction of azacyclopropane with azacyclopropenylidene may be one of the possible pathways to form the more complex nitrogen compounds, which are basic components for many biomolecules. In addition, given that azacyclopropane is the smallest $\mathrm{N}$-heterocyclic compound, it can be employed as a representative model molecule to study the formation of prebiotic species in interstellar space between azacyclopropenylidene and N-heterocyclic compound. In the present study, we have performed comprehensive theoretical investigation of the reaction mechanism between azacyclopropenylidene and azacyclopropane by employing the second-order Møller-Plesset perturbation theory (MP2) method in order to better understand the azacyclopropenylidene reactivity. The present results will enrich the available data for the relevant azacyclopropenylidene chemistry and discuss the possibility of formation of larger molecules by means of azacyclopropenylidene in interstellar space.

\section{CALCULATION METHOD}

The MP2 method in combination with $6-311+\mathrm{G}^{*}$ basis set has been employed to locate all the stationary points along the reaction pathways. Frequency analyses have been carried out to confirm the nature of the minima and transition states. Moreover, intrinsic reaction coordinate (IRC) calculations have also been performed to further validate the calculated transition states connecting reactants and products. Additionally, the relevant energy quantities, such as reaction energies and barrier heights, have been corrected with zeropoint vibrational energy (ZPVE) corrections.

To further refine the calculated energy parameters, single point energy calculations have been performed at the CCSD(T)/6-311+G* level of theory based on the stationary points optimized at the MP2/6-311+G* level of theory. As summarized in Table 1, both levels can give consistent results for the calculated reaction profile of the insertion reaction. For the sake of simplicity, the energetic results at the $\operatorname{CSS}(\mathrm{T}) / / \mathrm{MP} 2 / 6-31+\mathrm{G}^{*}$ level have been mainly discussed below if not noted otherwise.

To investigate the changes of the hybridization states of the selected atoms during the reaction, the natural bond orbital (NBO) analyses have been carried out on the basis of the optimized geometries. ${ }^{35}$

All the calculations have been performed using Gaussian 98 program $^{36}$. 


\section{RESULTS AND DISCUSSION}

As displayed in Scheme 2, two possible reaction pathways for the insertion reaction between azacyclopropenylidene and azacyclopropane have been proposed. The geometric parameters for the reactants (azacyclopropenylidene (R1) and azacyclopropane (R2)), transition states (TS), intermediates (IM), and products (P) involved in the pathways (1) and (2) are displayed in Figure 1. Correspondingly, the calculated relative energies for the available stationary points have been summarized in Table 1. The corresponding reaction profile is illustrated in Figure 2.

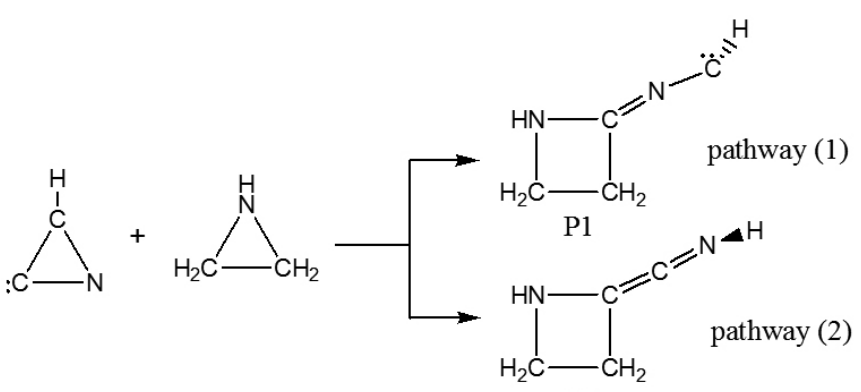

$\mathrm{P} 2$

Scheme 2. The proposed two reaction pathways for the insertion reaction between azacyclopropenylidene and azacyclopropane.

$$
\text { R1: azacyclopropenylidene } \mathbf{R}_{2: \text { azacyclopropane }}
$$

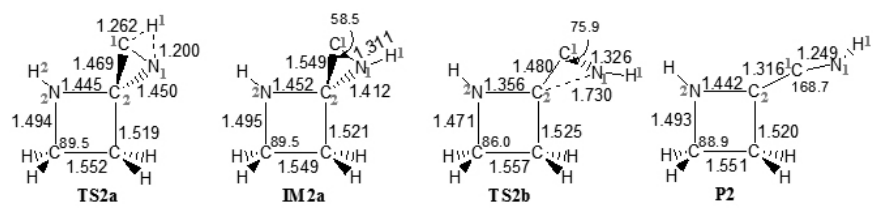

Figure 1. Optimized structures of the reactants (azacyclopropenylidene and azacyclopropane), transition states (TS), intermediates (IM), and product (P) in reaction pathways (1) and (2) at the MP2/6-311+G* level of theory, where the bond length and bond angle are in $\AA$ and degree, respectively.

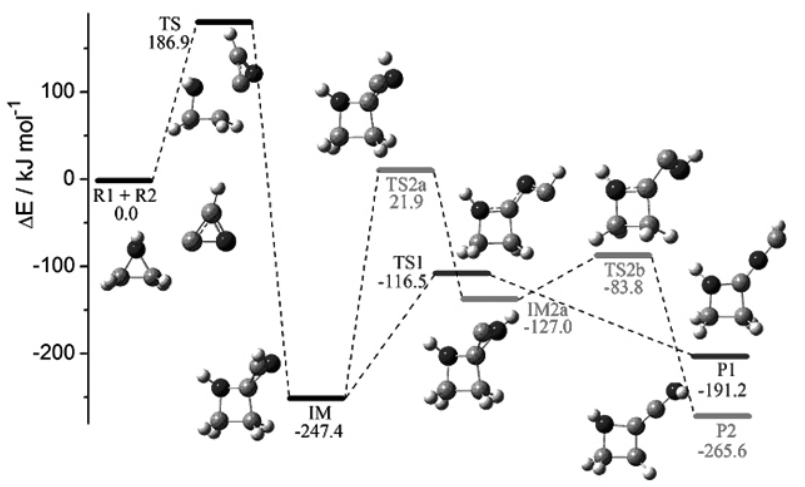

Figure 2. Reaction profile for the reaction between azacyclopropenylidene and azacyclopropane at the MP2/6-311+G* level of theory.
Table 1. The calculated relative energy (in $\mathrm{kJ} / \mathrm{mol}$ ) with respect to the isolated reactants at the MP2/6-311+G* level of theory considering the ZPVE corrections $^{a}$

\begin{tabular}{|c|c|c|c|c|}
\hline Pathways & \multicolumn{4}{|c|}{ Relative Energies } \\
\hline & TS & IM & & \\
\hline & $184.0(186.9)$ & $-267.2(-247.4)$ & & \\
\hline $\begin{array}{c}\text { Pathway } \\
(\mathbf{1})\end{array}$ & TS1 & P1 & & \\
\hline & $-115.1(-116.5)$ & $-189 . .8(-191.2)$ & & P2 \\
\hline $\begin{array}{c}\text { Pathway } \\
(\mathbf{2})\end{array}$ & TS2a & IM2a & TS2b & $\begin{array}{c}-274.4(- \\
265.6)\end{array}$ \\
\hline
\end{tabular}

a The data in the brackets refer to the results at the $\operatorname{CCSD}(\mathrm{T}) / / \mathrm{MP} 2 / 6$ $311+\mathrm{G}^{*}$ level of theory considering the ZPVE corrections.

\subsection{Insertion process to form a spiro intermediate IM}

The first intermediate IM in the reaction between azacyclopropenylidene and azacyclopropane has been formed via a barrier of $186.9 \mathrm{~kJ} / \mathrm{mol}$. The calculated unique imaginary frequency of the transition state TS in the insertion process is $756 \mathrm{i} \mathrm{cm}^{-1}$ at the MP2/6-311+G* level of theory.

As shown in Figure 1, in TS, the distance of $\mathrm{C}^{2}-\mathrm{N}^{2}$ is $2.245 \AA$, and $\mathrm{C}^{2}-\mathrm{C}^{4}$ is $1.900 \AA$. The distance of $\mathrm{N}^{2}-\mathrm{C}^{4}$ in $\mathrm{R} 2$ fragment of TS has been elongated significantly to $1.925 \AA$. Thus, in the transition state TS, two new bonds of $\mathrm{C}^{2}$ $\mathrm{N}^{2}$ and $\mathrm{C}^{2}-\mathrm{C}^{4}$ are to form and the $\mathrm{N}^{2}-\mathrm{C}^{4}$ bond is to break simultaneously. In other words, it's the process of $\mathrm{C}^{2}$ atom of $\mathrm{R} 1$ fragment insertion into the $\mathrm{N}^{2}-\mathrm{C}^{4}$ bond of R2 fragment that resulted the formation of a spiro intermediate IM. Moreover, as shown in Figure 3, those changes can be further validated by the IRC calculations on the basis of TS.
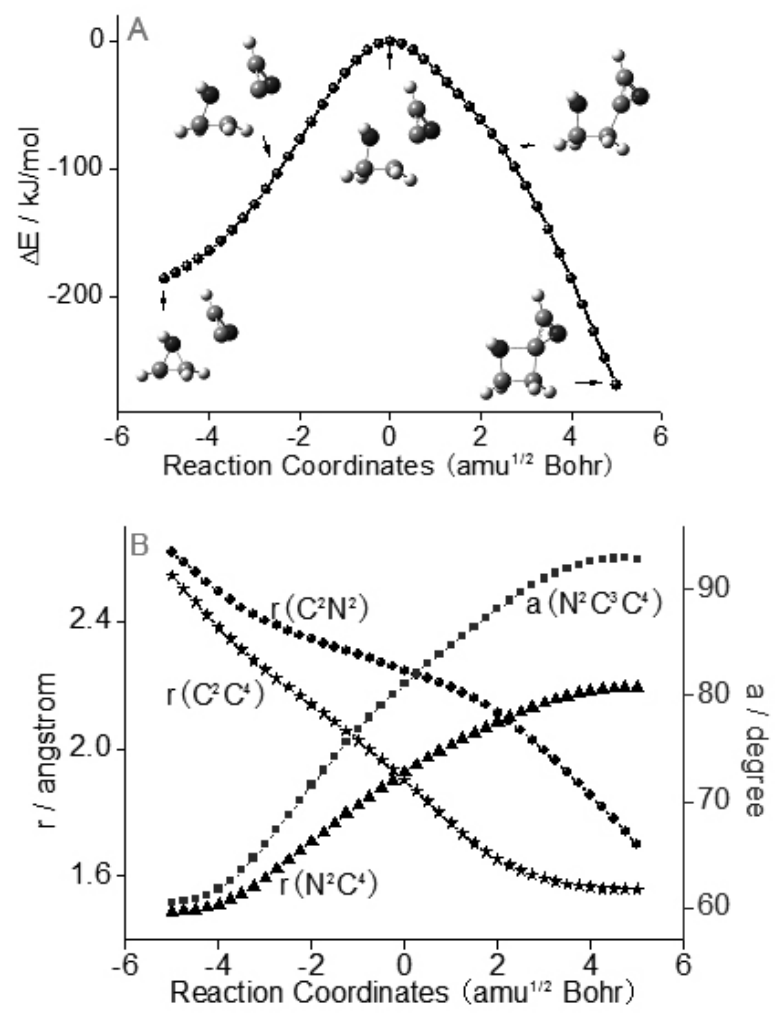

Figure 3. (A) IRC of TS and geometry evolution; (B) The selected bond lengths and bond angle changes along the reaction coordinates on the basis of the IRC of TS.

Qualitatively, we can explain the insertion process from the frontier molecular orbital theory since the frontier orbitals of a chemical species are 
very important to define their reactivity and determine the way in which the molecule interacts with other species ${ }^{37}$. It was found that the LUMO+1 orbital of azacyclopropane and the HOMO orbital of azacyclopropenylidene are relevant to the bond insertion process. As displayed in Figure 4, the weak strength of $\mathrm{C}-\mathrm{N}$ bond can be reflected from the LUMO+1 of azacyclopropane. On the contrary, the oppsite is true for the C-C bond. As for azacyclopropenylidene, the activity of $\mathrm{C}^{2}$ site can be reflected form the largest contributions on the $\mathrm{C}^{2}$ atom to the components of the whole HOMO. Therefore, the $\mathrm{C}^{2}$ atom in azacyclopropenylidene can insert into the $\mathrm{C}-\mathrm{N}$ bond of azacyclopropane rather than the $\mathrm{C}-\mathrm{C}$ bond.
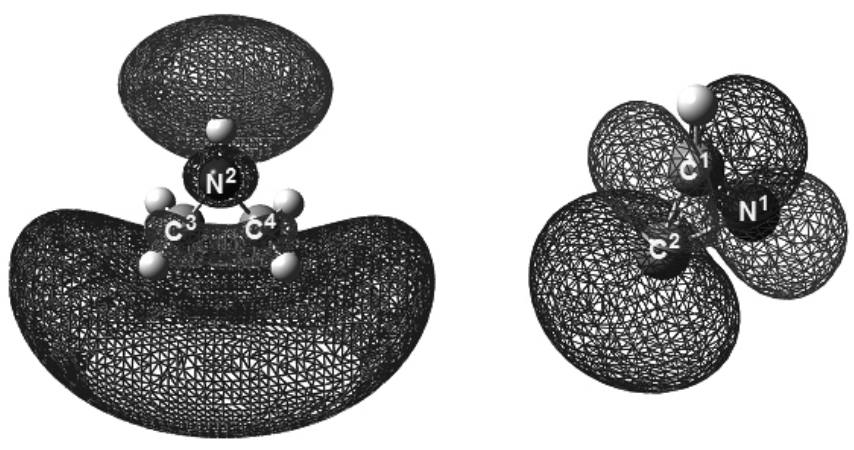

Figure 4. The calculated LUMO +1 orbital for azacyclopropane (left) and HOMO orbital for azacyclopropenylidene (right).

The hybridizaiton states of $\mathrm{N}^{1}$ and $\mathrm{C}^{1}$ atoms of IM employing the natural bond orbital (NBO) method have been investigated. It was found that the N1 and $\mathrm{C} 1$ atoms of IM adopt $s p^{2.27}$ and $s p^{2.50}$, respectively. Through the ringopened step at C-C bond, IM can transfer to product P1, which is named as pathway (1). On the other hand, through the $\mathrm{H}$-transferred step and subsequent ring-opened step at $\mathrm{C}-\mathrm{N}$ bond, IM can turn into product $\mathrm{P} 2$, which is named as pathway (2). Therefore, IM is the common intermediate for pathway (1) and pathway (2).

3.2 Pathway (1): ring-opened process to form a carbene product

As mentioned above, the first step of pathway (1) is the process of formation of IM. Through the cleavage of the $\mathrm{C}^{1}-\mathrm{C}^{2}$ bond, the second step of pathway (1) is that IM convert to P1 via TS1, where the barrier is $130.9 \mathrm{~kJ} /$ mol. The calculated only imaginary frequency of transition state TS1 is 394i $\mathrm{cm}^{-1}$. IRC calculations have been performed on the basis of the calculated TS1 to investigate the interactions between intermediate IM and product P1 in the pathway (1) process (see Figure 5).

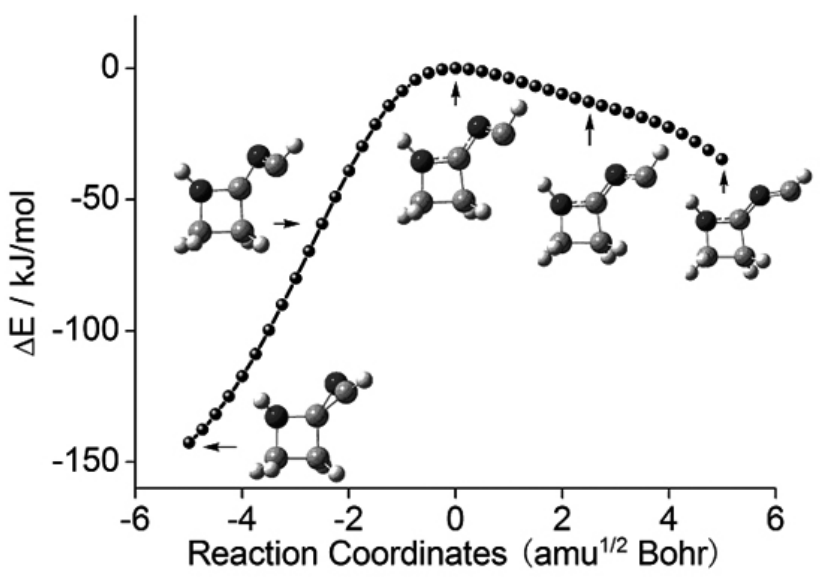

Figure 5. IRC of TS1 and geometry evolution.

As shown in Figure 1 and 5, for the angle of $\mathrm{C}^{1} \mathrm{~N}^{1} \mathrm{C}^{2}$ in TS1, it increases continuously along with the reaction. At the same time, the bond distance of $\mathrm{C}^{1}-\mathrm{C}^{2}$ increases along with the reaction process, implying the breakage of the three-membered ring involving $\mathrm{C}^{1} \mathrm{~N}^{1} \mathrm{C}^{2}$.
In $\mathrm{P} 1$, all the non-hydrogen atoms are located on the same plane approximately. The $\mathrm{N}^{1}$ atom adopts $s p^{2}$ hybridization and the bond length of $\mathrm{C}^{2}-\mathrm{N}^{1}$ is $1.267 \AA$, which is shorter than the normal $\mathrm{C}=\mathrm{N}$ double bond. On the other hand, the distance of $\mathrm{N}^{1}-\mathrm{C}^{1}(1.258 \AA)$ is shorter than the normal $\mathrm{N}-\mathrm{C}$ single bond. As for the $\mathrm{C}^{1}$ atom, it has a pair of lone electrons, making the $\mathrm{P} 1$ exhibit the carbene characters. Therefore, from the thermodynamics viewpoint, P1 is not a stable product, which can be demonstrated by the calculated energy $(-191.2 \mathrm{~kJ} / \mathrm{mol})$.

3.3 Pathway (2): H-transferred and ring-opened process to form an allene product

The second step and the third step of pathway (2) is the H-transferred process to form spiro intermediate IM2a, and the ring-opened process to form allene product $\mathrm{P} 2$, respectively.

The second step of pathway (2) is the hydrogen transfer from $\mathrm{C}^{1}$ to the adjacent $\mathrm{N}^{1}$, resulting in the conversion of IM into IM2a via TS2a. IRC calculations have been performed on the basis of the calculated TS2a in the pathway (2) process (see Figure 6). Here, the calculated barrier is $269.3 \mathrm{~kJ} /$ mol and the imaginary frequency of TS2a is $1356 \mathrm{i} \mathrm{cm}^{-1}$. In details, as shown in Figure 1 and Figure 6, the distance of $\mathrm{C}^{1}-\mathrm{H}^{1}$ in TS2a has been elongated to $1.262 \AA$, and the distance of $\mathrm{N}^{1}-\mathrm{H}^{1}$ reachs to $1.200 \AA$, indicating that the $\mathrm{H}^{1}$ atom can transfer from $\mathrm{C}^{1}$ to $\mathrm{N}^{1}$.

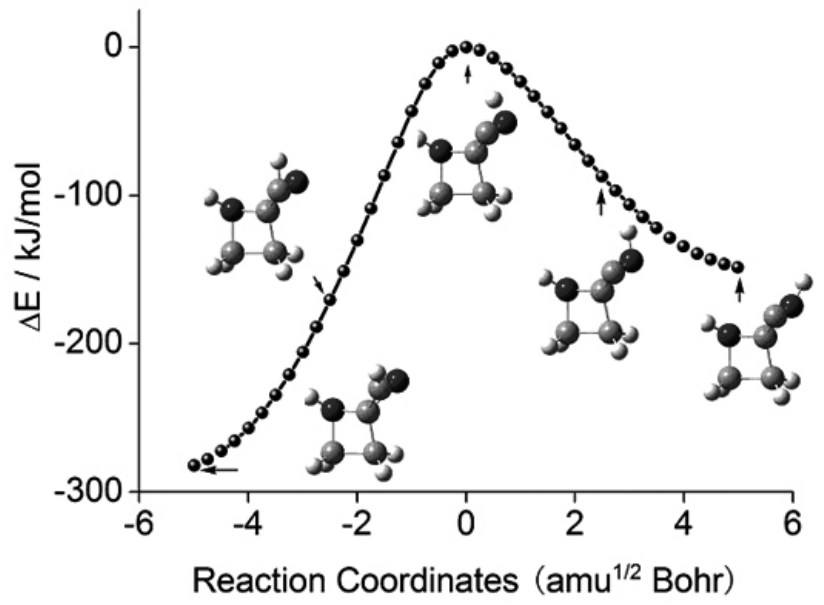

Figure 6. IRC of TS2a and geometry evolution.

Like as IM, IM2a is spiro intermediate. However, the bond between $\mathrm{C}^{1}$ and $\mathrm{N}^{1}$ in IM2a is single bond, whereas it is double bond in IM. Therefore, there are two unpaired electrons in $\mathrm{C}^{1}$ atom. In other words, IM2a has carbene characters, it is active and can convert into a more stable configuration.

The third step of pathway (2) is the ring-opened process to form allene product $\mathrm{P} 2$. Through the cleavage of the $\mathrm{C}^{2}-\mathrm{N}^{1}$ bond, IM2a converte into $\mathrm{P} 2$ via TS2b, where the barrier is $43.2 \mathrm{~kJ} / \mathrm{mol}$. The calculated one imaginary frequency of transition state TS $2 \mathrm{~b}$ is $475 \mathrm{i} \mathrm{cm}^{-1}$. As shown in Figure 1, the bond distance of $\mathrm{C}^{2}-\mathrm{N}^{1}$ in TS2b lengthens and the angle of $\mathrm{C}^{2} \mathrm{C}^{1} \mathrm{~N}^{1}$ increases along with the reaction process, implying the breakage of the three-membered ring involving $\mathrm{C}^{2} \mathrm{C}^{1} \mathrm{~N}^{1}$.

In $\mathrm{P} 2$, the bond length of $\mathrm{C}^{1}-\mathrm{C}^{2}$ is $1.316 \AA$, which fall in the range of the intermediate between $\mathrm{C}=\mathrm{C}$ and $\mathrm{C} \equiv \mathrm{C}$ bond length. Similarly, the bond length of $\mathrm{C}^{1}-\mathrm{N}^{1}(1.249 \AA)$ is in the middle of $\mathrm{C}=\mathrm{N}$ and $\mathrm{C} \equiv \mathrm{N}$ bond length. The three atoms, $\mathrm{C}^{2}, \mathrm{C}^{1}$, and $\mathrm{N}^{1}$, are almost in the same line (angle of $\mathrm{C}^{1} \mathrm{C}^{2} \mathrm{~N}$ is $168.7^{\circ}$ ). Therefore, $\mathrm{P} 2$ has the typical structure of allene. Along the reaction profile, $\mathrm{P} 2$ is the most stable species, which is exothermic with the value of $265.6 \mathrm{~kJ} / \mathrm{mol}$ compared with that of the reactants.

\section{CONCLUSIONS}

In this study, the reaction mechanism between azacyclopropenylidene and azacyclopropane has been systematically investigated employing the MP2/6$311+G^{*}$ level of theory. It is found that there are two pathways named (1) and (2) to form two ultimate products P1 and P2, respectively. The first step of the reaction is the formation of common intermediate IM. The barrier height of the rate-determining step in reaction pathway (1) and (2) is 186.9 , and 269.3 $\mathrm{kJ} / \mathrm{mol}$, respectively. Therefore, the reaction pathway (1) is the most favorable 
channel from the kinetic viewpoint. On the other hand, the corresponding two products $\mathrm{P} 1$ and $\mathrm{P} 2$ have been stabilized by about 191.2 and $265.6 \mathrm{~kJ} / \mathrm{mol}$ relative to the reactants, respectively. Therefore, the most favorable product P2 should be confirmed from the thermodynamical viewpoint.

\section{ACKNOWLEDGMENT}

This work is supported by NSFC $(21003082,21303093,21577076)$, the NSF of Shandong Province (ZR2014BM020), and the project of Shandong Province Higher Educational Science and Technology Program (J13LM06). The State Key Laboratory of Environmental Chemistry and Ecotoxicology, Research Center for Eco-Environmental Sciences, Chinese Academy of Sciences (KF2013-05) is also acknowledged.

\section{REFERENCES}

1. B. P. Joăo, S. Da, N. R. Mozart, Int. J. Quantum. Chem. 2, 215, (1992).

2. J. A. Francisco, S. L. Richardson, J. Chem. Phys. 9, 7707, (1994).

3. P. Botschwina, M. Horn, S. Seeger, J. Flugge, Mol. Phys. 1, 191, (1993).

4. P. Botschwina, B. Schulz, M. Horn, M. Matuschewski, Chem. Phys. 190, 345, (1995).

5. H. Suzuki, S. Yamamoto, M. Ohishi, N. Kaifu, S. Ishikawa, Y. Hirahara, S. Takano, Astrophys J. 392, 551, (1992).

6. H. E. Matthews, W. Irvine, P. Freiberg, R. D. Brown, P. D. Godfrey, Nature $310,125,(1984)$.

7. K. Aoki, S. Ikuta, A. Murakami, Chem. Phys. Lett. 3, 211, (1993).

8. K. Aoki, S. Ikuta, O. Nomura, J. Chem. Phys. 9, 7661, (1993).

9. W. M. Irvine, Adv. Space Res. 3, 35, (1995).

10. B. Lee, Chem. Phys. Lett. 1-2, 171, (1998).

11. S. Saito, K. Kawaguchi, S. Yamamoto, M. Ohishi, H. Suzuki, N. Kaifu, Astrophys. J. 317, L115, (1987).

12. M. B. Bell, L. W. Avery, A. Feldman, Astrophys. J. 417, L37, (1993).

13. S. Yamamoto, S. Saito, K. Kawaguchi, N. Kaifu, H. Suzuki, M. Ohishi, Astrophys. J. 317, L119, (1987).

14. K. Kim, B. Lee, S. Lee, Chem. Phys. Lett. 297, 65, (1998).

15. S. Lee, Chem. Phys. Lett. 1-2, 69, (1997).

16. M. Ohishi, N. Kaifu, K. Kawaguchi, A. Murakami, S. Saito, S. Yamamoto, S. I. Ishikawa, Y. Fujita, Y. Shiratori, W. M. Irvine, Astrophys. J. 345, L83, (1989).

17. M. B. Bell, P. A. Feldman, M. J. Travers, M. C. McCarthy, C. A. Gottlieb, P. Thaddeus, Astrophys. J. 483, L61, (1997).

18. D. McGonagle, W. M. Irvine, Astron. Astrophys. 310, 970, (1996).

19. M. C. McCarthy, C. A. Gottlieb, A. L. Cooksy, P. Thaddeus, J. Chem. Phys. 18, 7779, (1995).

20. N. Goldberg, A. Fiedler, H. Schwarz, J. Phys. Chem. 42, 15327, (1995).

21. K. Aoki, S. Ikuta, O. Nomura, J. Chem. Phys. 5, 3809, (1993).

22. F. Sun, A. Kosterev, G. Scott, V. Litosh, R. F. Curl, J. Chem. Phys. 20, 8851, (1998).

23. P. Y. Hung, F. Sun, N. T. Hunt, L. A. Burns, R. F. Curl, J. Chem. Phys. 20, 9331, (2001).

24. J. E. Rice, H. F. Schaefer, J. Chem. Phys. 12, 7051, (1987).

25. E. T. Seidl, H. F. Schaefer, J. Chem. Phys. 6, 4449, (1992).

26. P. Sung-Woo, L. Sungyul, Bull. Korean Chem. Soc. 11, 1553, (2002).

27. I. Natalia, H. Xinchuan, J. L. Timothy, J. Chem. Phys. 135, 244310, (2011).

28. M. Z. Kassaee, S. M. Musavi, N. Jalalimanesh, J. Theor. Comput. Chem. 3, $367,(2008)$.

29. M. Z. Kassaee, M. Ghambarian, S. M. Musavi, Heteroatom Chem. 4, 377, (2008).

30. K. Jacek, J. Phys. Chem. A 107, 4717, (2003).

31. G. Maier, H. P. Reisenauer, K. Rademacher, Chem. Eur. J. 10, 1957, (1998).

32. G. Maier, A. Bothur, J. Eckwert, H. P. Reisenauer, Chem. Eur. J. 10, 1964, (1998).

33. N. Balucani, M. Alagia, L. Cartechini, P. Casavecchia, G. G. Volpi, K. Sato, T. Takayanagi, Y. Kurosaki, J. Am. Chem. Soc. 18, 4443, (2000).

34. M. R. Nimlos, G. Davico, C. M. Geise, P. G. Wenthold, W. C. Lineberger, S. J. Blanksby, C. M. Hadad, G. A. Petersson, G. B. Ellison, J. Chem. Phys. 9, 4323, (2002)

35. A. E. Reed, L.A. Curtiss, F. Weinhold, Chem. Rev. 88, 899, (1988).

36. Frisch MJ, Trucks GW, Schlegel HB, Scuseria GE, Robb MA, Cheeseman JR, Zakrzewski VG, Montgomery JA, Stratmann RE, Burant JC, Dapprich S, Millam JM, Daniels AD, Kudin KN, Strain MC, Farkas O, Tomasi J,
Barone V, Cossi M, Cammi R, Mennucci B, Pomelli C, Adamo C, Clifford S, Ochterski J, Petersson GA, Ayala PY, Cui Q, Morokuma K, Malick DK, Rabuck AD, Raghavachari K, Foresman JB, Cioslowski J, Ortiz JV, Stefanov BB, Liu G, Liashenko A, Piskorz P, Komaromi I, Gomperts R, Martin RL, Fox DJ, Keith T, Al-Laham MA, Peng CY, Nanayakkara A, Gonzalez C, Challacombe M, Gill PM, Johnson BG, Chen W, Wong MW, Andres JL, Head-Gordon M, Replogle ES, Pople JA (1998) Gaussian 98, revision A.9; Gaussian, Inc.: Pittsburgh, PA

37. P. Thaddeus, C. A. Gottlieb, R. Mollaaghababa, J. M. Vrtilek, J. Chem. Soc. Faraday Trans. 89, 2125, (1993). 